Esta revista forma parte del acervo de la Biblioteca Jurídica Virtual del Instituto de Investigaciones Jurídicas de la UNAM

\title{
RESTRICCIONES INDIRECTAS AL EJERCICIO DEL DERECHO A LA LIBERTAD DE EXPRESIÓN. COMENTARIO AL CASO GRANIER Y OTROS (RADIO CARACAS TELEVISIÓN) VS. VENEZUELA
}

Víctor Hugo Hiram MagaLLANES MARTíNEZ*

\section{Abreviaturas y Siglas}
$\mathrm{ADC}$
Asociación por los Derechos Civiles.
$\mathrm{CIDH}$
Comisión Interamericana de Derechos Humanos.
$\mathrm{CoIDH}$
Corte Interamericana de Derechos Humanos.
RCTV
Radio Caracas Televisión.
RELE
Relatoría Especial para la Libertad de Expresión.
SIDH
Sistema interamericano de derechos humanos.

\section{INTRODUCCIÓN}

Es una realidad que la región latinoamericana presenta serios problemas normativos e institucionales a la hora de hacer efectivos los derechos humanos, y esto se debe, en gran medida, a la transición de los Estados hacia la democracia representativa. Finalizaron las dictaduras y nacieron sistemas democráticos con la esperanza de ver cesadas las violaciones a derechos, creando así un nuevo escenario político regional.

Víctor Abramovich sostiene la existencia de una complejidad del actual escenario político regional, pues muchos de los países latinoamericanos no

* Licenciado en derecho; Juzgado Tercero de Distrito en el Estado de Morelos; biktor25@hotmail.com.

Fecha de recepción: 8 de diciembre de 2016.

Fecha de dictamen: 18 de julio de 2017. 
Esta revista forma parte del acervo de la Biblioteca Jurídica Virtual del Instituto de Investigaciones Jurídicas de la UNAM

han logrado consolidar sus sistemas democráticos que, si bien han dado algunos pasos, presentan serias deficiencias institucionales y tienden a manifestar altos niveles de desigualdad y exclusión (2009: 18).

Siguiendo a este autor, en el actual escenario social, los órganos del sistema interamericano de derechos humanos, que están conformados por la Comisión Interamericana de Derechos Humanos y por la Corte Interamericana de Derechos Humanos, se han esforzado no sólo por impulsar los medios de reparación a víctimas en casos particulares, sino que se han enfocado en fijar un cuerpo de principios y estándares con el propósito de tener una mayor incidencia en el fortalecimiento de los procesos de la sociedad (Abramovich, 2009: 10).

No se puede negar que los criterios emitidos por los órganos que integran el SIDH inciden a la hora en que un Estado fija sus políticas; incluso, estos juicios fijan pautas, lineamientos básicos o estándares que de cierta forma varían la agenda estatal en el análisis, adopción, formulación e implementación de políticas públicas que sirven de medio para garantizar un mejor ejercicio de los derechos humanos.

En este momento se preguntará el lector: ¿qué relación tiene lo narrado en líneas anteriores con el caso que se comenta? Por sus lineamientos, lo resuelto por la Corte Interamericana en el Caso Granier y otros (Radio Caracas Televisión) vs. Venezuela, aparte de seguir la postura que respecto al tema de restricciones indirectas ha planteado la Relatoría Especial para la Libertad de Expresión a través de diversos informes, tiene un impacto persuasivo dentro de la región, en la medida en que, ante la problemática derivada del abuso de controles oficiales para limitar la libertad de expresión, hace un llamado hacia la construcción de una nueva agenda de acciones de política pública relativas a este tópico y la prohibición de censura previa.

El tema abordado por la CoIDH no fue sencillo, pues si bien en la región latinoamericana han sido reconocidos ciertos progresos en el ejercicio de la libertad de expresión, tratándose de censura indirecta los avances han sido significativamente escasos, al grado que actualmente se realizan prácticas que son heredadas por sistemas dictatoriales que no permiten el ejercicio libre de la expresión discrepante o crítica a posturas oficiales. Una de esas prácticas es, como se puso de manifiesto en el caso que se comenta, lo que ha sido denominado como "censura sutil", en la que el Estado, con la finalidad de prohibir la difusión de comentarios apartados a su línea política, utiliza sus facultades para alinear editorialmente al medio de comunicación. 
Esta revista forma parte del acervo de la Biblioteca Jurídica Virtual del Instituto de Investigaciones Jurídicas de la UNAM

Así, lo resuelto en el Caso Granier y otros (Radio Caracas Televisión) vs. Venezuela constituye un precedente muy favorable para erradicar la censura previa y de intervención de los gobiernos en las bases editoriales de las empresas de comunicación, pues retoma una problemática regional y convoca a la construcción de una nueva agenda de acciones por parte de los Estados, en su intento de dar respuesta a uno de los problemas institucionales que, como se ha expuesto en líneas anteriores, aquejan al SIDH.

\section{LIBERTAD DE EXPRESIÓN Y RESTRICCIONES INDIRECTAS}

DE ESTE DERECHO EN EL SISTEMA INTERAMERICANO

La libertad de expresión nace y evoluciona como consecuencia del intercambio de ideas, opiniones e informaciones entre las personas, lo que hace posible que todos los seres humanos progresen y se desarrollen (Rodríguez, 2015: 49), de ahí que se le vincule regularmente con el concepto de democracia como aspecto integrante del Estado de derecho, porque en la medida en que el ser humano es capaz de recibir información y comunicar sus ideas de manera plural, puede comprender los procesos políticos y participar de manera activa en la construcción de una sociedad democrática.

De acuerdo con Cossío Díaz, el Estado de derecho es una construcción lingüística de carácter social mediante la cual se busca que los órganos estatales lleven a cabo determinadas actuaciones y omitan otras, en aras de preservar cierto entendimiento del hombre y del papel que respecto del mismo debe cumplir el Estado; por ello, calificarlo como "de derecho" implica asignar un valor positivo a las prácticas institucionales que, de modo general, llevan a cabo los titulares de los órganos del Estado, y otorgar legitimación a éstos por la forma en que realizan sus acciones (Cossío, 2008: 100-116).

Así, el "Estado de derecho" cumple con ciertas atribuciones que, en simples palabras, se traducen en eficacia burocrática, efectividad en el sistema normativo, credibilidad del discurso y realidad de las contribuciones del filtraje; sin embargo, el concepto de "Estado democrático de derecho" contiene algunas otras, entre las que en forma destacada se encuentra la sanción y garantía de los derechos políticos básicos favorecidos por la democracia.

Dicho de otra forma, se traduce en la defensa de los derechos a participar libremente y sin coacciones en las elecciones razonablemente limpias y competitivas, así como también en sancionar y brindar protección en torno a los derechos de asociación, de opinión, de expresión, de movimiento 
Esta revista forma parte del acervo de la Biblioteca Jurídica Virtual del Instituto de Investigaciones Jurídicas de la UNAM

y otros, sin los cuales las elecciones no serían limpias ni competitivas, esto sin que nadie, ni siquiera los gobernantes, queden fuera de la legalidad (O’Donnell, 2008: 89-99).

Entonces, bajo el concepto de "Estado democrático de derecho" es que se contempla a la libertad de expresión que, en palabras de Thomas Emerson, está integrada por un conjunto de derechos que van desde el derecho a formarse y poseer las propias creencias y comunicarlas por cualquier medio, pasando por los de audiencia e investigación y de acceso a la información, hasta los derechos de reunión y asociación (Luna, 2014: 342). Siguiendo a este mismo autor, es claro que este derecho es un método que asegura una comunidad estable, donde la búsqueda del consenso se transforma en el elemento fundamental de la democracia (Fernández, 2001).

Por los motivos que han sido expuestos, el derecho a la libertad de expresión surge como una exigencia para la adopción de reglas normativas y políticas públicas, con el claro objetivo de fomentar la difusión de ideas entre particulares y entre éstos y el sector público y, aunque existen ciertas teorías para tratar este derecho - derivativas o deontológicas, entre otras- que lo tratan de enfocar más a los conceptos de promoción de la verdad, de la autonomía de la decisión o de un fin en sí mismo, lo cierto es que la que ha tenido una mayor aceptación entre los tribunales nacionales e internacionales es la que se pronuncia a favor de su vinculación con la participación democrática, en tanto que debe considerarse que los ciudadanos deben ser expuestos a una amplia variedad de puntos de vista y posiciones respecto de los diversos temas para poseer la información necesaria en la toma de decisiones (Loreti y Lozano, 2014: 36).

Siguiendo con estas ideas, la CoIDH ha establecido qué es lo que debe entenderse por libre expresión y ha partido de la base de que este derecho es bidimensional. Según ha sostenido la jurisprudencia interamericana (CoIDH, 2001: párrafos 31-33; CoIDH, 2014: párrafo 371), la libertad de expresión puede ser vista en su faz individual, que es el derecho de cada persona a utilizar cualquier medio apropiado para difundir sus opiniones, y la segunda con su referente social, que se encamina a la idea de satisfacer las necesidades de todos los ciudadanos de recibir información y opiniones diversas, es decir, a estar bien informados, aspectos que también han sido destacados por la Comisión Interamericana (CIDH, 2010: 5).

En el caso que se comenta, también la CoIDH dejó muy clara su postura en torno a la doble dimensión del derecho a la libre expresión (CoIDH, 2015: párrafo 135) resaltando los estándares interamericanos establecidos respecto a este derecho, lo que nos proporciona una idea bastante clara de la proyección que quiere dar, en la medida en que impone la obligación 
Esta revista forma parte del acervo de la Biblioteca Jurídica Virtual del Instituto de Investigaciones Jurídicas de la UNAM

a los Estados de garantizarlo y resguardarlo desde diversas perspectivas para evitar cualquier clase de restricción arbitraria, tomando como base la idea de que existen actores de este derecho de diversa índole, posiciones y pretensiones. Sin embargo, ¿qué hay de las restricciones indirectas al ejercicio de este derecho?, ¿existen estándares básicos que planteen la problemática derivada de la censura previa o del abuso de los controles oficiales? Como se precisó en el apartado introductorio, este tema es complejo y el trabajo realizado por la RELE, por la academia y, no está por demás decirlo, por la sociedad civil, ha sido sumamente importante y progresivo.

En efecto, desde el ámbito académico se ha establecido que la obligación de proscribir las restricciones indirectas a la libertad de expresión es muy relevante, al grado que si bien es cierto los documentos del SIDH en la materia aluden expresamente a una fuente "clásica" de restricciones indirectas, el Estado tiene que emprender acciones para inhibirlas en la medida que, para cumplir con su deber de garantía, debe atajar y bloquear las acciones que puedan disminuir o imposibilitar el ejercicio de la libertad de expresión (Pou, 2013: 919).

Respecto a este tipo de restricción indirecta, también la sociedad civil ha señalado de manera enfática que, de acuerdo con su naturaleza, es una práctica que aqueja a la mayor parte de América Latina y permanece invisible para el público en general, mientras se concreta una amplia e insidiosa sombra sobre la libertad de expresión (ADC, 2008: 7).

Así, para cierto sector de la sociedad, y en específico desde el ámbito periodístico, el hecho de que las restricciones indirectas no hayan sido consideradas hasta ahora no significa que no se generen; mejor dicho, son de difícil ubicación y además aún existe debate sobre cómo o qué herramientas utilizar para restringirlas (Sapiezynska, 2013: 12).

Como ya ha sido plasmado, esta circunstancia también es advertida por la RELE, quien ha expuesto cómo se debieran emitir medidas para combatir la censura previa, por lo que se refiere al ejercicio indebido o abusivo de controles oficiales para limitar la libre difusión de ideas.

En efecto, en lo relativo al tema de desviación de poder por parte de los Estados al utilizar una facultad que les es permitida (control y administración del espacio radioeléctrico), la Relatoría Especial, como órgano de la CIDH, ha señalado que para hacer frente a este problema es necesario que los Estados adopten normas que impidan que en un futuro, cualquiera de sus agentes, pueda usar arbitrariamente el poder de regulación para silenciar la expresión disidente, haciendo patente que se requiere de normas claras y precisas que establezcan de manera certera las atribuciones de regulación de las autoridades; facultades que deben perseguir un 
Esta revista forma parte del acervo de la Biblioteca Jurídica Virtual del Instituto de Investigaciones Jurídicas de la UNAM

fin legítimo y ser estrictamente necesarias para el logro del fin propuesto (CIDH, 2003: 23).

Asimismo, la Relatoría Especial ha expuesto la necesidad de promover estándares que permitan guiar las actuaciones de los gobiernos y que, sin obstaculizar el cumplimiento de la tarea de aplicar la ley y de defender por vías legítimas los diversos puntos de vista contra ataques que consideran injustos, realicen actuaciones que impidan utilizar un poder para evitar la circulación libre y desinhibida de todas las expresiones e informaciones (CIDH, 2009: 29).

Así, siendo concretos, la Relatoría Especial ha precisado que aparte de las violaciones directas, coexisten otras indirectas (más sutiles) que también son contrarias a lo señalado en el artículo 13 de la Convención Americana sobre Derechos Humanos, y que las define como "todo acto del poder público que implique una restricción al derecho de buscar, recibir y difundir informaciones e ideas, en mayor medida o por medios distintos de los autorizados por la misma Convención” (CIDH, 2010: 32).

Para este órgano del CIDH, una forma de restringir indirectamente el ejercicio del derecho a la libertad de expresión es cuando se otorgan o se retiran frecuencias de radio y televisión con el claro objetivo de privilegiar o presionar a los medios de comunicación en función de sus líneas editoriales. Obviamente existen más situaciones que constituyen restricciones indirectas; sin embargo, considero que en este ensayo el lector debe enfocarse a este tipo de limitación, pues constituye la esencia del caso que se comenta.

Ahora bien, derivado de numerosas denuncias que se han dado en la región latinoamericana en lo que se refiere al control de los medios oficiales, la CIDH, a través de la RELE, ha exteriorizado ciertas medidas que deben adoptar los Estados, con la finalidad de prevenir la posibilidad de utilización de atribuciones estatales para premiar o castigar a los medios de información y para fomentar el pluralismo y la diversidad en el debate público. Estas medidas son de abstención, regularización de políticas de conformidad con los estándares interamericanos, y de adopción de legislación para regular las facultades estatales de control y vigilancia, así como de asignación de recursos públicos relacionados con el ejercicio de la libertad de expresión (CIDH, 2015: 395).

Asimismo, la Relatoría Especial ha presentado como parte de su "agenda hemisférica” el planteamiento de que, para lograr una asignación no discriminatoria de los bienes o recursos públicos, es necesaria la existencia de marcos regulatorios que obliguen a los Estados a someterse a una normatividad precisa que impida la discrecionalidad en la concesión de frecuencias de radio y televisión (CIDH, 2010: 28). 
Esta revista forma parte del acervo de la Biblioteca Jurídica Virtual del Instituto de Investigaciones Jurídicas de la UNAM

Hasta aquí no queda duda sobre la problemática advertida tanto por la sociedad civil, la academia, la CIDH y la RELE; sin embargo, ¿cuál es la postura de la CoIDH sobre este tema?, ¿qué situaciones constituyen restricciones indirectas al ejercicio del derecho a la libertad de expresión? Sobre este tópico, en la Opinión Consultiva OC-5/85, del 13 de noviembre de 1985, la Corte Interamericana expuso que constituye una restricción indirecta al ejercicio de la libre expresión el que trate de justificarse la colegiación obligatoria del periodismo en razones de orden público, toda vez que se limita de modo permanente, en perjuicio de quienes no cuentan con dicha colegiación, el derecho de ejercer de manera efectiva las facultades que reconoce el artículo 13 de la Convención (CoIDH, 1985: párrafos 48 y 76).

Por otra parte, en el Caso Ivcher Bronstein vs. Perú, la CoIDH se pronunció en torno a que constituye una restricción indirecta a la libertad de expresión el uso arbitrario de las facultades regulatorias del Estado cuando son ejercidas para intimidar a un medio de comunicación (CoIDH, 2001: párrafos 158-163). También ha precisado que existe otra forma de restricción indirecta cuando, mediante declaraciones de funcionarios públicos, se pueden originar formas de injerencia directa o indirecta, o presión lesiva en los derechos de quienes pretenden contribuir a la deliberación pública mediante la expresión y difusión de su pensamiento (CoIDH; 2009: párrafo 151), y también cuando se exige de acreditaciones de manera desproporcionada o discriminatoria a los medios de prensa para la participación en eventos oficiales (CoIDH, 2009: párrafo 375).

Las determinaciones descritas en párrafos que anteceden dan cuenta del arduo trabajo que ha desempeñado la CoIDH al tratar el tema de las restricciones indirectas. Los planteamientos que han sido sometidos a su conocimiento son muy variados y atienden a diversas problemáticas que se van generando con el paso del tiempo. Por esta razón, el caso que se comenta es trascendental, en la medida que se aboca a los temas de abuso de controles oficiales y pluralismo informativo como nuevas áreas de implementación de estándares interamericanos.

III. El CONTEXTO DEL CASO: Un GOLPE DE Estado FALlido Y LA TENSIÓN ENTRE EL GOBIERNO Y LOS MEDIOS DE COMUNICACIÓN

Para tener una mejor comprensión del caso que se comenta, es necesario tener en mente un panorama general del escenario político en Venezuela, lo 
Esta revista forma parte del acervo de la Biblioteca Jurídica Virtual del Instituto de Investigaciones Jurídicas de la UNAM

que aconteció en dicho país entre 2002 y 2003, así como cuáles fueron los hechos probados ante la Corte Interamericana.

En términos generales, en Venezuela ha imperado un clima de hostigamiento, violencia e intimidación hacia los medios de comunicación. Este panorama ha sido motivo de pronunciamiento de los órganos que integran el SIDH.

Por ejemplo, en el informe anual de 2003, la CIDH, a través de la RELE, mostró su preocupación al pronunciarse en el sentido de que en Venezuela no se registra un clima de tolerancia en el cual se favorezca la activa participación e intercambio de ideas de los diversos sectores de la sociedad - y, además, que los actos de violencia en contra de periodistas y medios

- de comunicación, en relación con su trabajo, así como las declaraciones descalificatorias de altos funcionarios públicos, configuran un escenario restrictivo que continúa inhibiendo el ejercicio de la libertad de expresión (RELE, 2003: 10).

Esta inquietud ha sido reiterada por la RELE en diversos informes anuales, e invita a la reflexión sobre lo que se vive en aquel país, el cual no ha superado en gran medida los rasgos que distinguen a un sistema dictatorial que ha perjudicado de manera seria su composición, al grado de que parte de sus habitantes se cuestionan si en realidad viven en una democracia (porque eligieron a sus gobernantes) o en una dictadura (al carecer de libertad de expresión).

Ése ha sido el panorama de los últimos años en Venezuela; constantes inconformidades que se exteriorizan con movilizaciones, pero que son seguidas de actos de opresión perpetrados por las autoridades, lo cual no permite un ejercicio efectivo de la democracia deliberativa que se estatuye en su ley fundamental.

En el caso que se comenta, el clima de violencia se desencadenó porque entre diciembre de 2001 y abril de 2002 se produjo una movilización social de diferentes sectores de la población en contra de diversas políticas del gobierno venezolano. El movimiento se originó tras la aprobación de 49 leyes económicas, entre ellas la Ley de Tierras y la Ley de Hidrocarburos, que fue lo que provocó un paro nacional convocado el 10 de diciembre de 2001, en el que tuvieron intervención distintos sectores comerciales y empresariales, como lo son los medios de comunicación.

El 11 de abril de 2002 fue desconocida la autoridad de Hugo Chávez Frías como presidente del Estado de Venezuela, y al día siguiente el General Lucas Rincón informó a la población que se solicitó su renuncia, la cual había aceptado, por lo que en la madrugada del día siguiente se anunció la disolución de los poderes públicos y el establecimiento de un "gobierno 
Esta revista forma parte del acervo de la Biblioteca Jurídica Virtual del Instituto de Investigaciones Jurídicas de la UNAM

de transición democrática”; sin embargo, el 14 de abril de ese año, Hugo Chávez fue restablecido en la Presidencia de la República, de ahí que el movimiento social descrito se considerara, por la posición institucional, como "una interrupción abrupta del orden democrático y constitucional".

Con la llegada de Chávez de nueva cuenta al poder no terminaría el conflicto, pues según el contenido del informe titulado "Carne de cañón" de 2002 y el que fuera denominado como "Estática en Venezuela" de 2007, existieron ataques físicos hacia los periodistas, que a la postre llevarían a la decisión del gobierno de no renovar la concesión de espectro radioeléctrico a Radio Caracas Televisión (COJ, 2012).

En efecto, Radio Caracas Televisión fue señalada por funcionarios estatales como una de las emisoras privadas de televisión que fueron partícipes políticos activos en los hechos del golpe de Estado de abril de 2002, en especial porque apoyó de manera amplia al paro que tuvo lugar entre finales 2001 y comienzos de 2002, de ahí que, como se mencionó en el párrafo anterior, aun cuando se interpusieron recursos antes y después del cierre de transmisiones, no se le otorgó el derecho de renovar la concesión de espectro radioeléctrico, incluso aunque llegase a compararse en niveles de audiencia con una distinta emisora a la cual sí se le renovó su concesión.

En lo que se refiere a los hechos que emergen de manera directa del caso, la Corte Interamericana tuvo como probada la existencia de una situación de tensión con posterioridad al golpe de Estado, durante la cual se dio una polarización política que tuvo su origen en una notoria tendencia a la radicalización de las posturas de los sectores involucrados; es decir, un contexto marcado por un discurso insistente por parte del gobierno venezolano que acusaba a los medios de comunicación privados, entre ellos RCTV, de "ser enemigos del gobierno", "golpistas" y "fascistas", y de causarle "un gravísimo daño psicológico al pueblo venezolano" (CoIDH, 2015: párrafos 60 y 61).

Entonces, bajo dichos argumentos y ante el concepto de "un golpe mediático" o un "golpe empresarial", el Estado de Venezuela procuró silenciar a todo aquel que tuviera ideas diferentes a sus políticas de gobierno, y uno de los métodos para realizar tal represión fue no renovar la concesión de uso de espectro radioeléctrico a quienes hubieran tenido algún papel protagonista en los conflictos sociales mencionados; es decir, hacer uso del propio sistema para impedir la difusión de información proveniente de quienes mantuvieran alguna disidencia ideológica y política a la del Estado. En síntesis, lo descrito en las últimas líneas son los hechos que la Corte Interamericana tuvo por probados, esto es, que en Venezuela impera un clima de hostigamiento hacia los medios de comunicación tras los ante- 
Esta revista forma parte del acervo de la Biblioteca Jurídica Virtual del Instituto de Investigaciones Jurídicas de la UNAM http://www.juridicas.unam.mx/ DOI: http://dx.doi.org/10.22201/iij.25940082e.2018.5.12124

cedentes ocurridos entre 2001 y 2002 y que como medio de hostigamiento se hizo uso de las facultades regulatorias de las frecuencias radioeléctricas para impedir que se difundieran ideas ajenas a la corriente política del Estado (CoIDH, 2015: párrafos 60 y 61).

\section{El debate jurídico planteado ante la Corte} INTERAMERICANA Y LA SOLUCIÓN DEL CASO

El desarrollo del caso fue sumamente complejo, lo que generó una extensa

- deliberación entre los jueces interamericanos, y provocó que la mayoría se - diera a la tarea de elaborar votos individuales concurrentes y disidentes.

En síntesis, la CoIDH se pronunció de manera significativa respecto al tema de la libertad de expresión en relación con el derecho a la igualdad y las restricciones indirectas en el ejercicio del primero. Asimismo, dentro de las determinaciones reveladoras se encuentra la que concierne al derecho a renovación de licencias y sus diferencias con la figura de la preferencia. Por ello, en el presente ensayo sólo se abordarán los temas descritos, sin incluir los pronunciamientos realizados sobre la posible violación a las garantías judiciales y protección judicial para evitar cualquier tipo de confusión.

Pues bien, las posturas de las partes fueron muy variadas, tanto de la CIDH, de los representantes de las presuntas víctimas y del Estado, lo que dio pauta a que la CoIDH adoptara diversas determinaciones. Por ejemplo, por lo que respecta a la violación a la libertad de expresión, la CIDH alegó que la asignación del espectro radioeléctrico, con el objeto de presionar o privilegiar a los comunicadores sociales y a los medios de comunicación, constituye una restricción indirecta a la libertad de expresión prohibida por el artículo 13.3 de la Convención Americana, lo que genera también un efecto silenciador en otros medios de comunicación y que impacta severamente la libertad de expresión en su dimensión social. También, en torno a violaciones dentro del procedimiento de renovación de la concesión, planteó que dicha contienda se dio en un amplio margen de inseguridad, debido a la falta de claridad de la normativa aplicable. Estos planteamientos fueron coincidentes con la postura de los representantes de la víctima, aunque estos últimos agregaron que el hecho de que no se renovara la concesión significaba el alto índice de dominación del gobierno respecto a su otorgamiento.

Por su parte, el Estado hizo diversas manifestaciones en torno a que el argumento según el cual "la decisión del Estado venezolano de no re- 
Esta revista forma parte del acervo de la Biblioteca Jurídica Virtual del Instituto de Investigaciones Jurídicas de la UNAM

novar la concesión de RCTV para operar como estación televisiva tenía por objeto silenciar dicho medio de comunicación por difundir opiniones críticas e informaciones contrarias al gobierno" sería desvirtuado con el hecho de que otras televisoras habían renovado su concesión para el uso del espectro radioeléctrico. En ese sentido, señaló que la determinación de no renovación se debía al incumplimiento de normas y principios de ética periodística.

Con base en estos planteamientos, el desarrollo argumentativo de la Corte Interamericana comenzó con el enfoque clásico de la fijación de los estándares interamericanos respecto al ejercicio de la libertad de expresión y su ejercicio por personas físicas y jurídicas; partió de la idea de que las restricciones a la libertad de expresión frecuentemente se concretan a través de acciones del Estado o de particulares que afectan no sólo a la persona jurídica que constituye un medio de comunicación, sino también a la pluralidad de personas naturales, tales como accionistas o los periodistas que ahí laboran y que realizan actos de comunicación a través de la misma, de ahí que sea necesario que los periodistas gocen de la protección y de independencia suficientes para llevar a cabo sus funciones en virtud de que son éstos los que mantienen informada a la sociedad.

El apartado descrito refleja la posición de la CoIDH para reconocer la situación de periodistas que han sido limitados en el ejercicio de su derecho a ejercer una libre expresión, por ello explicó la conexión que existe entre estos agentes de la información con las emisoras de telecomunicaciones, y puso mayor énfasis en la facultad de todos (personas físicas y jurídicas) de ser consideradas como víctimas en la medida de las funciones que desempeñaban, obviamente si dicha relación se encontraba acreditada.

Siguiendo con su línea argumentativa, la CoIDH fijó su postura en torno a las restricciones indirectas, de las cuales detalló que, de acuerdo con la interpretación del artículo 13.3 en relación con el 13.1 de la Convención Americana sobre Derechos Humanos, queda prohibido el empleo de "vías o medios indirectos" para restringir la comunicación, difusión y circulación de ideas y opiniones. Por ello, en lo que respecta al espacio radioeléctrico, precisó que es un bien escaso con un número determinado de frecuencias, lo que limita el número de medios que pueden acceder a ellas, de ahí que sea fundamental asegurar que en ese número de medios se halle representada una diversidad de visiones o posturas informativas o de opinión.

Ante tal panorama, la CoIDH señaló que es necesario que los Estados prevean de manera clara en sus ordenamientos jurídicos los procesos que versen sobre el otorgamiento o renovación de concesiones o licencias rela- 
Esta revista forma parte del acervo de la Biblioteca Jurídica Virtual del Instituto de Investigaciones Jurídicas de la UNAM

cionadas con la actividad de radiodifusión, mediante criterios objetivos que eviten la arbitrariedad; de manera específica — recalcó- es preciso que se establezcan las salvaguardas o garantías generales de debido proceso, con la finalidad de evitar el abuso de controles oficiales y la generación de posibles restricciones indirectas.

En una diversa propuesta, la CIDH y los representantes de la víctima cuestionaron lo alegado por el Estado, en el sentido de que la no renovación de la concesión provenía de "la democratización del uso del medio radioeléctrico y la pluralidad de los mensajes y contenidos”, y para ello señalaron que dicha motivación no era real, en todo caso habría material probatorio para acreditar que se trataba de un tipo de sanción hacia RCTV por difundir contenidos no apegados a la línea editorial del Estado. Tras un recuento del acervo probatorio, la CoIDH determinó que la finalidad declarada por el Estado no era cierta y que por ello se configuraba una desviación de poder, ya que se hizo uso de una facultad permitida del Estado con el objetivo de alinear editorialmente al medio de comunicación con el gobierno.

De igual manera, tanto la Comisión Interamericana como los representantes de la víctima argumentaron que se violó lo dispuesto por el artículo 24 de la Convención Americana sobre Derechos Humanos, porque al otorgar el Estado una renovación de la concesión a otras empresas, se había configurado un trato discriminatorio sin una base objetiva para realizar tal distinción, a lo que el Estado argumentó que no se violó tal precepto convencional porque las empresas, en las que todavía tenían participación accionaria Marcel Granier, Peter Bottone y Jaime Nestares, continúan funcionando, difundiendo sus puntos de vista y comercializando sus productos en el territorio venezolano sin ninguna restricción.

En razón a la argumentación anterior, la CoIDH señaló que no se configuraban hechos relativos a una protección desigual derivada de una ley interna, por ello no correspondía analizar la presunta violación del derecho a la igual protección de la ley contenido en el artículo 24 de la Convención, pero que analizaría únicamente la alegada violación al deber de respetar y garantizar sin discriminación los derechos contenidos en la Convención Americana, establecido en el artículo 1.1 de la Convención, en relación con el derecho a la libertad de expresión de las presuntas víctimas.

Bajo esta idea, la CoIDH estableció que la línea editorial de un canal de televisión es el reflejo de la expresión de las personas involucradas con el diseño de dicha línea, por lo que puede ser objeto de un trato discriminatorio debido a sus opiniones políticas. En ese sentido, determinó que el gobierno, al realizar un trato diferenciado basado en el agrado o disgusto 
Esta revista forma parte del acervo de la Biblioteca Jurídica Virtual del Instituto de Investigaciones Jurídicas de la UNAM

que le causaba la corriente ideológica de un canal, conlleva a que se genere un efecto disuasivo, atemorizador e inhibidor sobre todos los que ejercen el derecho a la libertad de expresión, ya que envía un mensaje amedrentador para los otros medios de comunicación respecto a lo que les podría llegar a ocurrir en caso de seguir una línea política como la de RCTV, por tanto que el Estado venezolano fuera responsable internacionalmente de la violación del derecho a la libertad de expresión establecido en el artículo 13 en relación con el deber de no discriminación contenido en el artículo 1.1 de la Convención Americana.

Por otra parte, los representantes de la víctima argumentaron que la vulneración al derecho a la libertad de expresión se habría producido por el incumplimiento de la normativa interna e internacional, según la cual se desprendería un derecho a la renovación de la concesión.

Respecto a este planteamiento, la CoIDH fue enfática en determinar que el derecho a la preferencia reviste una naturaleza completamente distinta al derecho de renovación, pues la primera se refería a un tratamiento especial o diferenciado que puede o no otorgarse, es decir, una expectativa de derecho, y que no había en el ordenamiento jurídico interno disposición que mencionara que el Estado estuviera obligado a conceder la renovación o alguna prórroga automática.

Así, señaló que el espectro radioeléctrico es un bien jurídico cuyo dominio corresponde al Estado, y por tanto su titularidad no puede ser reclamada por los particulares; por ello, que al no existir un derecho a la extensión automática de concesiones en la normativa venezolana, el uso de este espacio no puede ser considerado como un bien o derecho adquirido ya incorporado a la empresa.

Es común para quienes realizan un servicio, una obra pública o explotan algún bien, estimen que les asiste un derecho de propiedad sobre dicha actividad. Sin embargo, debe recordarse que quien confiere la realización de esas acciones es el Estado, el cual, a través de la figura de la concesión, encomienda al particular a su realización por un tiempo determinado. Una vez que le es otorgada a un particular la atribución de prestar un servicio o explotar un bien, el Estado aún conserva sus facultades para revisar el cumplimiento a las disposiciones que regulan esta prestación o explotación, es decir, el aprovechamiento de la concesión, y la renovación está sujeta a la revisión y control del cumplimiento de las disposiciones aplicables, obviamente si existe alguna norma que contenga dicho derecho.

Por ello, la prestación del servicio público es una actividad sujeta, en cuanto a su organización, funcionamiento y relaciones con los usuarios, a un régimen de derecho público, destinado a satisfacer una concreta y per- 
Esta revista forma parte del acervo de la Biblioteca Jurídica Virtual del Instituto de Investigaciones Jurídicas de la UNAM

manente necesidad colectiva, cuya atención corresponde a la administración pública. En este orden, dado que la concesión siempre versará sobre bienes o servicios cuyo aprovechamiento y explotación corresponden al Estado, los particulares no cuentan con un derecho preexistente para exigirla ni para cuestionar su otorgamiento, salvo que se trate del concesionario contratante, quien tiene, sólo si la legislación lo permite, el derecho a renovar su concesión a través de la figura de la preferencia; es decir, una vez que se revisa el cumplimiento a las disposiciones que regulan la actividad, el Estado puede aplicar un trato diferenciado a favor del concesionario para darle cierta ventaja sobre las demás personas simplemente por su po- sición. De esto se sigue que el Estado, a través de la concesión, no otorga - un derecho de propiedad a favor del particular.

En ese contexto es plausible la determinación de la CoIDH, pues, por un lado, señala que sí se concretaron restricciones indirectas al ejercicio de la libertad de expresión relacionado con el diverso derecho a la igualdad, pero también dejó muy clara su postura de que a Radio Caracas Televisión no le asistía un derecho de propiedad ni de renovación automática porque no había regulación en tal sentido.

Como se ve, son múltiples los temas que le fueron propuestos a la Corte Interamericana; sin embargo, los que considero trascendentales son los descritos en líneas anteriores, pues son los que dan pauta a que se realice una reflexión profunda sobre las preocupaciones en nuestro actual escenario regional.

\section{IMPORTANCIA DE LA SENTENCIA EN EL ACTUAL ESCENARIO REGIONAL}

El fallo en comento tiene trascendencia regional, pues, en primer lugar, se retoma el tema del abuso de los controles oficiales y el pluralismo informativo, que si bien había sido abordado en casos anteriores, ahora se proyecta hacia la creación de mejores prácticas en el ejercicio del derecho a la libertad de expresión y, en segundo término, refleja la intención de incorporar nuevas ideas en la formación de estándares para fortalecer el compromiso de los Estados para garantizarlo.

En efecto, con los pronunciamientos realizados en el caso que se comenta, si bien se reconoció la potestad y necesidad que tienen los Estados para regular la actividad de radiodifusión, también es verdad que se estableció el imperativo de implementar políticas públicas sobre dicha actividad, pero delimitadas por los lineamientos que genera el ejercicio del derecho a la libertad de expresión. 
Esta revista forma parte del acervo de la Biblioteca Jurídica Virtual del Instituto de Investigaciones Jurídicas de la UNAM

Además, para efectos de contar con estándares adecuados a la realidad actual, la CoIDH puso un mayor énfasis en que el pluralismo de ideas en los medios no se puede medir a partir de la cantidad de medios de comunicación, sino de que las ideas y la información transmitidas sean diversas y que provengan de posturas variadas que inviten a la integración de una mejor crítica, lo que denota la intención de la CoIDH de seguir forjando estándares en los cuales se haga patente la participación del ciudadano en la toma de decisiones en un Estado democrático de derecho, independientemente de si el gobierno se siente atacado por diferentes ideologías a las que va encaminada su línea política. Lo anterior porque, de acuerdo con cierto sector del ámbito académico, la importancia del pluralismo informativo radica en que existan diferentes fuentes de información y corrientes de opinión que le permitan al ciudadano asumir un juicio equilibrado y razonado sobre la cosa pública (Rodríguez, 2015: 49), pero con este fallo se incorpora otra idea, que es la de que el derecho a la libertad de expresión debe ser protegido por razones imparciales. En esa medida, cualquier regulación deberá compartir dichas finalidades.

Aunado a lo anterior, como se había comentado al inicio de este ensayo, con esta resolución la CoIDH retoma un tema que es preocupante en el SIDH y manda un claro mensaje para que los Estados, a través de sus políticas públicas, integren a su agenda la adecuada regulación del uso del espectro radioeléctrico para evitar violaciones al derecho a la libertad de expresión.

En cualquier caso, tanto la situación del acceso de los medios como el tema de la renovación o revocación de las concesiones han puesto la atención de los organismos internacionales de derechos humanos sobre cómo los Estados otorgan las frecuencias de radio y televisión, y cómo utilizando una potestad legítima y legal se puede llegar a casos de violación de la libertad de expresión (Ávila et al., 2011: 152).

Claramente existen mensajes de inconformidad por parte de periodistas, medios de comunicación y órganos cuasi-jurisdiccionales en el sentido de que el control editorial que ejerce el poder político es una realidad, y al parecer estos mensajes han encontrado oídos en la resolución emitida por la Corte Interamericana, pues a través de ella se configuran una serie de estándares de gran relevancia para la región, que al mismo tiempo contribuyen al respeto y garantía de los derechos en los procedimientos para el otorgamiento o renovación de concesiones en materia de telecomunicaciones.

Como se dijo anteriormente, la CoIDH determinó declarar responsable internacionalmente al Estado venezolano por considerar que no se había respetado el ejercicio del derecho a la libertad de expresión, y aunque falta 
Esta revista forma parte del acervo de la Biblioteca Jurídica Virtual del Instituto de Investigaciones Jurídicas de la UNAM

un gran camino por recorrer, la decisión tomada en el Caso Granier y otros (Radio Caracas Televisión) vs. Venezuela refleja la intención de la CoIDH de dejar un precedente claro para la edificación de una sociedad más democrática, en la que se privilegie en forma real este derecho por sobre cualquier interés a través de instrumentos, leyes y políticas públicas que garanticen de manera efectiva el pluralismo de información como condición necesaria para la consolidación de una democracia constitucional.

Debo insistir que esta resolución solamente constituye un paso para obtener el fin propuesto y es plausible la intención de la CoIDH al fijar estándares en cuanto al derecho a la libertad de expresión, pero también - considero que la armonía en su ejercicio radica en la correcta convivencia - de los sujetos que integran la relación tripartita que se mencionó en párrafos que anteceden.

En efecto, en la resolución de la CoIDH se determinó la existencia de una necesidad de los Estados para regular la actividad de radiodifusión, con base en una planificación e implementación de políticas públicas que respeten el derecho a la libertad de expresión, pero esta regulación sería solamente el instrumento por el cual los sujetos deben hacer respetar sus derechos; entonces, de manera complementaria a lo expuesto en la sentencia que se comenta, es conveniente un cambio de actitud en el Estado, en los medios de comunicación y en los propios integrantes de la colectividad.

Lo anterior porque si queremos que el pluralismo sea más eficiente, se requiere, en primer lugar, de una actitud de servicio por parte del Estado, en donde no imperen sus intereses; mejor dicho, lo que debe prevalecer son criterios encaminados a fortificar la capacidad de discernimiento de cada uno de los miembros de la sociedad; además, también es necesario que los medios de comunicación brinden contenidos amplios y no marcados con una sola tendencia política, ideológica o cultural; en sí, que la información provenga de todas las fuentes que éste disponga y también que sea veraz, y, finalmente, también es importante que la ciudadanía muestre su interés en los distintos campos que le rodean, pues una sociedad mejor informada puede tener un mayor juicio sobre los contenidos que recibe.

En otras palabras, es necesario que estos tres pilares sobre los que se constituye el derecho a la libertad de expresión en su dimensión social adopten un compromiso con el bien de la sociedad.

Estas son algunas reflexiones sobre lo que representa el ejercicio de la libertad de expresión, y quizá solamente sean el punto de partida para poner en movimiento a los diversos actores y abordar los desafíos que ya se plantean para los años por venir (Loreti y Lozano, 2014: 268) para así 
Esta revista forma parte del acervo de la Biblioteca Jurídica Virtual del Instituto de Investigaciones Jurídicas de la UNAM

lograr un verdadero sistema democrático, en la medida en que el tema que queda pendiente es qué herramientas en específico se deben utilizar para inhibir el uso de restricciones indirectas.

\section{Fuentes de información}

Abramovich, Víctor, 2009, "De las violaciones masivas a los patrones estructurales: nuevos enfoques y clásicas tensiones en el sistema interamericano de derechos humanos", Revista Internacional de Derechos Humanos, núm. 11.

Ackerman, John M. et al. (coords.), 2008, Más allá del acceso a la información. Transparencia, rendición de cuentas y Estado de derecho, México, Siglo XXI Editores.

Asociación por los Derechos Civiles (ADC), 2008, El precio del silencio: abuso de publicidad oficial y otras formas de censura indirecta en América Latina, Argentina.

Ávila Ordoñez, María Paz et al. (coords.), 2011, Libertad de expresión: debates, alcances y nueva agenda, Ecuador.

Bogdandy, Armín von et al. (coords.), 2012, Igualdad y orientación sexual. El caso Atala de la Corte Interamericana de Derechos Humanos y su potencial, México, Porrúa.

Comisión Interamericana de Derechos Humanos (CIDH), 2010, Relatoría especial para la libertad de expresión, "Una agenda hemisférica para la defensa de la libertad de expresión", Organización de Estados AmericanosComisión Interamericana de Derechos Humanos.

Comisión Interamericana de Derechos Humanos (CIDH), 2010, Relatoría especial para la libertad de expresión, "Estándares de libertad de expresión para una radiodifusión libre e incluyente", Organización de Estados Americanos-Comisión Interamericana de Derechos Humanos.

Comisión Interamericana de Derechos Humanos (CIDH), 2011, Relatoría especial para la libertad de expresión, "El derecho de acceso a la información en el marco jurídico interamericano", 2a. ed., Organización de Estados Americanos-Comisión Interamericana de Derechos Humanos.

Comisión Interamericana de Derechos Humanos (CIDH), 2015, Relatoría especial para la libertad de expresión, "Informe anual de la Comisión Interamericana de Derechos Humanos 2015", Organización de Estados Americanos-Comisión Interamericana de Derechos Humanos. 
Esta revista forma parte del acervo de la Biblioteca Jurídica Virtual del Instituto de Investigaciones Jurídicas de la UNAM http://www.juridicas.unam.mx/ DOI: http://dx.doi.org/10.22201/iij.25940082e.2018.5.12124

Committee to Рвотест Journalists, 2012, Medios privados venezolanos se debilitan bajo asedio de Chávez, un informe especial del Comité para la Protección de los Periodistas.

Corte Interamericana de Derechos Humanos (CoIDH), 1985, Opinión Consultiva OC-5/85, "La colegiación obligatoria de periodistas (artículos 13 y 29 Convención Americana sobre Derechos Humanos)", 13 de noviembre de 1985 .

Corte Interamericana de Derechos Humanos (CoIDH), 2001, Caso "La última tentación de Cristo" (Olmedo Bustos y otros vs. Chile).

- Corte Interamericana de Derechos Humanos (CoIDH), 2001, Caso Iv- cher Bronstein vs. Perú.

Corte Interamericana de Derechos Humanos (CoIDH), 2009, Caso Perozo y otros vs. Venezuela.

Corte Interamericana de Derechos Humanos (CoIDH), 2014, Caso Norín Catrimán y otros vs. Chile.

Corte Interamericana de Derechos Humanos (CoIDH), 2015, Caso Granier y otros (Radio Caracas Televisión) vs. Venezuela.

Cossío Díaz, José Ramón, 2008, “Transparencia y Estado de derecho”, en Ackerman, John M. et al. (coords.), Más allá del acceso a la información. Transparencia, rendición de cuentas y Estado de derecho, México, Siglo XXI Editores.

Fernández Bogado, Benjamín, 2001, El poder político y el derecho a la información, Sala de Prensa, núm. 27, año III, vol. 2, enero.

Loreti, Damián y Lozano, Luis, 2014, El derecho a comunicar. Los conflictos en torno a la libertad de expresión en las sociedades contemporáneas, Argentina, Siglo Veintiuno Editores.

Luna Pla, Issa, 2014, "Derecho a la información (jurisprudencia constitucional)", en Ferrer Mac-Gregor, Eduardo et al. (coords.), 2014, Diccionario de derecho procesal constitucional y convencional, México, Instituto de Investigaciones Jurídicas.

O’Donnell, Guillermo, 2008, "Democracia y Estado de derecho", en ACKerman, John M. et al. (coords.), Más allá del acceso a la información. Transparencia, rendición de cuentas y Estado de derecho, México, Siglo XXI Editores.

Pou GiménEz, Francisca, 2013, "La libertad de expresión y sus límites”, en Ferrer Mac-Gregor, Eduardo et al. (coords.), Derechos humanos en la Constitución: comentarios de jurisprudencia constitucional e interamerica- 
Esta revista forma parte del acervo de la Biblioteca Jurídica Virtual del Instituto de Investigaciones Jurídicas de la UNAM

na, México, Suprema Corte de Justicia de la Nación-Fundación Konrad Adenauer-UNAM, Instituto de Investigaciones Jurídicas.

Rodríguez Lozano, Luis Gerardo, 2015, La libertad de expresión como requisito esencial para la garantía de las libertades informativas, México, Fontamara.

Salvioli, Fabián y Zanghí, Claudio et al. (coords.), 2013, Jurisprudencia regional comparada de derechos humanos. El Tribunal Europeo y la Corte 119 Interamericana, México, Tirant lo Blanch.

SAPIEZYNSKA, Ewa et al., 2013, Libertad de prensa bajo presión: niveles de restricción percibidos por periodistas chilenos y factores influyentes, Cuadernos.info, 32, 11-26. DOI: 10.7764/cdi.32.468, disponible en: http:// cuadernos.info/index.php/CDI/article/view/468/pdf. 